\title{
O CNPQ NA CONJUNTURA ATUAL: RELATO DE EXPERIÊNCIA COMO REPRESENTANTE DE ÁREA
}

Denise Elias ${ }^{1}$

Resumo: $\mathrm{C}$ CNPq é a principal agência de fomento à pesquisa do Brasil e desempenha papel primordial na formulação e na condução das políticas de ciência, tecnologia e inovação. Sua atuação é estruturante para o avanço das fronteiras do conhecimento e, assim, para o desenvolvimento e a soberania do país. Mas tudo isto hoje está em risco, dado o atual contexto político nacional, considerando os cortes no orçamento da instituição, comprometendo a continuidade do papel que a mesma desempenha. O objetivo principal do texto é compartilhar inquietações vividas a partir de minha atuação como representante da Geografia Humana no Comitê de Assessoramento da Cosae no CNPq e, dessa forma, contribuir com o debate sobre o tema.

Palavras-chave: CNPq. Ciência. Pesquisa científica. Fomento. Brasil.

\section{CNPQ IN THE CURRENT CONJUNCTURE: AREA REPRESENTATIVE EXPERIENCE REPORT}

Abstract: $\mathrm{CNPq}$ is the main research funding agency in Brazil and plays a key role in formulating and conducting science, technology and innovation policies. Its performance is structuring for the advancement of the frontiers of knowledge and, thus, for the development and sovereignty of the country. But nowadays all of this is at risk, given the current national political context, considering the cuts in the institution's budget, compromising the continuity of the role it plays. The main objective of the article is to share concerns experienced during my performance as a representative of Human Geography in the Advisory Committee of Cosae at CNPq and, thus, contribute to the debate on the topic.

Keywords: CNPq. Science. Scientific research. Funding. Brazil.

\section{EL CNPQ EN LA COYUNTURA ACTUAL: INFORME DE EXPERIENCIA COMO REPRESENTANTE DEL ÁREA}

Resumen: CNPq es la principal agencia de promoción de investigación en Brasil y juega un papel importante en la formulación y conducción de políticas de ciencia, tecnología e innovación. Su desempeño se estructura para el avance de las fronteras del conocimiento y, por lo tanto, para el desarrollo y la soberanía del país. Pero todo esto hoy está en riesgo, dado el contexto político nacional actual, considerando los recortes en el presupuesto de la institución, comprometiendo la continuidad del papel que desempeña. El objetivo principal del texto es compartir las preocupaciones experimentadas por mi actuación como representante de Geografía Humana en el Comité Asesor de Cosae en CNPq y, por lo tanto, contribuir al debate sobre el tema.

Palabras clave: CNPq. Ciencias. Investigación científica. Promoción. Brasil.

\footnotetext{
${ }^{1}$ Universidade Estadual do Ceará, Programa de Pós Graduação em Geografia, Fortaleza, Brasil, deniseliasgeo@gmail.com, 0000-0002-8384-0990
} 


\section{Introdução²}

O presente ensaio é uma síntese de nossa fala em mesa redonda durante o II Seminário de Pós-Graduação em Geografia no Brasil, promovido pela Associação Nacional de Pós-Graduação e Pesquisa em Geografia (ANPEGE). ${ }^{3}$ Seu objetivo principal é compartilhar uma série de inquietações vividas recentemente, especialmente nos últimos quatro anos, visando incrementar o debate sobre 0 fomento à pesquisa científica no Brasil na atual conjuntura política, abarcando especificamente o Conselho Nacional de Desenvolvimento Científico e Tecnológico $(\mathrm{CNPq}){ }^{4}$

Mister se faz destacar que eu não falo em nome do CNPq. Tais questões são levantadas a partir de minha atuação como membro representante da Geografia Humana $(\mathrm{GH})$ no Comitê de Assessoramento (CA) da Coordenação do Programa de Pesquisa em Ciências Sociais Aplicadas e Educação (Cosae), especificamente no CA - SA, que reúne a Arquitetura, Demografia, Geografia, Turismo e Planejamento Urbano e Regional. ${ }^{5}$

Inicialmente, quando parei para pensar em qual seria o viés para minha fala no evento, a ideia era centrá-la especialmente mostrando a importância da instituição através de dados da evolução do fomento à ciência e tecnologia no Brasil. Pensei em construir gráficos e tabelas com os dados da evolução do fomento à pesquisa e à pós-graduação, visando evidenciar a relevância do CNPq para a ciência brasileira. Mas, logo em seguida, considerando o momento político atual do país, pareceu-me que, mais importante do que estatísticas ou outras métricas sobre a evolução do orçamento, das bolsas etc., seria utilizar outros elementos de

\footnotetext{
${ }^{2}$ Agradeço a leitura e comentários dos professores Dra. Doralice Sátyro Maia (UFPB) e Dr. Renato Pequeno (UFC), mas gostaria de eximi-los de qualquer responsabilidade pelas ideias apresentadas.

${ }^{3}$ O seminário ocorreu na cidade de São Paulo, de 25 a 27 de fevereiro de 2019. A mesa teve como título As Políticas de Fomento à Pesquisa e Pós-Graduação no Brasil na Atual Conjuntura. O presente texto é uma versão revisada da publicação original nos Anais do II Seminário de PósGraduação e Pesquisa em Geografia no Brasil, no mesmo ano.

${ }_{4} \mathrm{O}$ CNPq esteve associado ao Ministério da Ciência, Tecnologia e Inovação até o golpe político de 2016. Com a reformulação da estrutura ministerial ocorrida então, transformou-se em uma agência do Ministério da Ciência, Tecnologia, Inovações e Comunicações (MCTIC).

${ }^{5}$ Sou representante da Geografia Humana no CNPq desde final de 2014. No primeiro momento como suplente da professora Sandra Lencioni (USP) e desde meados de 2017 como Coordenadora da área de Geografia Humana, tendo como suplente a professora Monica Arroyo (USP). Vale destacar que, muito embora exista oficialmente a figura do representante e do suplente, temos trabalhado sem seguir tal hierarquia, a não ser em situações que exista a exigência do CNPq para tal. Meu mandato se encerra em meados de 2020. Aproveito para dizer também, visando ampliar o conhecimento, que os membros dos comitês de assessoramento do CNPq são eleitos pelos pesquisadores bolsistas de produtividade - PQ - nível 1 e têm 'mandato' de três anos. Da mesma forma, somente os PQs 1 podem ser eleitos. É uma atividade sem vínculo empregatício e sem remuneração.
} 
argumentação. Até mesmo porque, com um pouco de esforço, qualquer pessoa pode ter acesso a vários destes dados consultando a página do CNPq. ${ }^{6}$

Contribuíram também para a decisão sobre o conteúdo de minha fala as que me antecederam, especialmente a do presidente da Sociedade Brasileira para o Progresso da Ciência (SBPC), que tão bem apresentou alguns dados sobre a evolução (e recente queda) das finanças no CNPq. Assim, a opção recaiu sobre uma fala baseada mais na experiência vivida como representante no $C A$, já que aqui poderia contribuir socializando informações restritas a um número bem menor de pessoas e, desta forma, quem sabe, despertar os colegas para o que me parece uma grave situação. Talvez o ensaio tenha ficado com um tom intimista demais, quase uma "contação de história" em alguns momentos, mas a história precisa ser contada para ser conhecida e, para o caso presente, na perspectiva de que seja transformada.

Quando parei para organizar minha fala no evento, foi como se passasse um filme retrospectivo dos caminhos por mim trilhados na pesquisa científica, já que minha história está, direta e indiretamente, bastante imbricada ao CNPq, uma vez que fui bolsista da instituição de várias modalidades, em diferentes momentos, e até hoje como bolsista de produtividade.

Foi através do CNPq, por exemplo, que cheguei ao Ceará, nos anos 1990, com uma bolsa de Desenvolvimento Científico e Regional (DCR), para ficar um ano e lá estou até hoje. Esta modalidade, ainda pouco conhecida pela comunidade acadêmica, tem como objetivo principal a descentralização dos doutores e a fixação dos mesmos nas regiões mais carentes de tais profissionais, ou seja, Norte, Nordeste e Centro-Oeste. Vejam que a realidade da pós-graduação do Brasil mudou radicalmente desde então, a ponto de hoje parecer pouco significativo tal tipo de modalidade de bolsa, e o CNPq tem enorme participação nesta mudança.

Como podem ver, equivoquei-me considerando que falaria apenas a partir de meu papel como representante de área, falo como pesquisadora para a qual o CNPq fez a diferença. Imagino que como eu, vários dos que agora leem este texto também tiveram suas vidas profundamente transformadas pelas possibilidades de formação abertas pela instituição. Isto nas mais diferentes modalidades de fomento, desde as bolsas do $\mathrm{Pibic}^{7}$, de mestrado, de doutorado, as bolsas especiais (professor visitante, pós-doutorado, doutorado pleno no exterior, doutorado sanduíche), os

\footnotetext{
${ }^{6}$ A página do CNPq possui um conjunto de informações sobre investimento em CT\&I, especialmente para o período de 2000 a 2015.

7 Programa Institucional de Bolsas de Iniciação Científica.
} 
auxílios à pesquisa, a participação em eventos no exterior, auxílio à realização de eventos, dentre tantas outras modalidades.

Tudo isto hoje está em risco, dado o atual contexto político nacional, que promove cortes de verba, especialmente desde o golpe travestido de impeachment da Presidenta Dilma Rousseff em 2016, comprometendo a continuidade do papel que o CNPq desempenha há décadas de forma tão importante.

Isto significa que a ciência e a universidade pública brasileira estão em risco. E a considerar o panorama político atual, especialmente as ciências humanas, as sociais aplicadas, a educação e as artes que, de maneira geral, sempre sofrem mais com os cortes, por serem consideradas não prioritárias para o desenvolvimento do país e especialmente agora, com o novo grupo à frente do executivo federal, que elegeu tais setores como as verdadeiras "bruxas modernas".

Desta forma, neste artigo apresento algumas de minhas inquietações resultantes de atuação como representante da área de Geografia Humana junto ao CNPq. Além desta introdução, o texto é composto por outras três seções. A primeira faz uma brevíssima síntese do papel do CNPq para a ciência, a tecnologia e a inovação no país. No intuito de evidenciar aspectos da situação hoje vigente na instituição - o principal objetivo deste ensaio - a segunda seção abarca aspectos da história recente da mesma, tendo o ano de 2016 como ponto de inflexão. Nesta seção trabalho a hipótese de que o CNPq estaria passando por um processo de "corrosão" e apresento alguns elementos de argumentação. Não por acaso, esta seção acabou sendo a maior do texto. Por último, como palavras finais, termino pensando em quais seriam algumas das perspectivas para mudança do quadro presente.

\section{Um pouco de história ${ }^{8}$}

O CNPq foi criado em 1951 e é a principal agência de fomento à pesquisa do país, desempenhando papel primordial na formulação e na condução das políticas de ciência, tecnologia e inovação desde então. De acordo com informações do próprio site da instituição, como principais atribuições tem o fomento à pesquisa científica, tecnológica e à inovação, visando incentivar a formação de pesquisadores brasileiros, contribuindo, assim, para o avanço das fronteiras do conhecimento e soberania nacional.

\footnotetext{
8 Para a redação desta seção foram consultados alguns sites, tais como o do próprio CNPq, da Fapesp, da Funcap, da SBPC, entre outros.
} 
Concede bolsas para a formação de recursos humanos no campo da pesquisa científica e tecnológica, em universidades, institutos de pesquisa, centros tecnológicos e de formação profissional, tanto no Brasil como no exterior. Sua atuação contribui para o desenvolvimento nacional e o reconhecimento das instituições de pesquisa e dos pesquisadores brasileiros pela comunidade científica internacional.

O financiamento da pesquisa no Brasil se dá por meio de diferentes sistemas e instituições de fomento, que estão ligadas direta ou indiretamente aos ministérios brasileiros. Os financiamentos institucionais, por exemplo, são provenientes do Fundo Nacional de Desenvolvimento Científico e Tecnológico (FNDCT), um fundo público alimentado pelos chamados fundos setoriais de ciência e tecnologia, ${ }^{9}$ os quais arrecadam recursos de vários setores da iniciativa privada.

Por outro lado, quase todos os estados do Brasil têm suas próprias fundações de apoio à pesquisa (FAPs). A Fundação de Amparo à Pesquisa do Estado de São Paulo (Fapesp) é, sem dúvida, a mais forte delas e chega a ter editais de grande monta de recursos, tais como os Projetos Temáticos, objeto de desejo de muitos pesquisadores. A promulgação da Constituição Federal de 1988 foi importante no fortalecimento das FAPs, pois, mesmo que facultativo, possibilitou a vinculação de parcela das receitas orçamentárias a entidades públicas de fomento ao ensino e à pesquisa científica e tecnológica. Alguns deputados federais, como o sociólogo Florestan Fernandes, e entidades tais como a SBPC, tiveram papel importante na luta que se travou por ocasião da Constituinte na década de 1980. 10

Hoje, vários dos editais das fundações estaduais, especialmente das FAPs com menos recursos, são totalmente vinculados às verbas repassadas, por exemplo, pelo CNPq. Isto se deve até mesmo porque várias destas FAPs, muito embora tenham em suas Constituições Estaduais um percentual da arrecadação tributária destinada às pesquisas científicas e tecnológicas, nem sempre têm tais regras seguidas pelos governos estaduais. ${ }^{11}$ Alguns editais, que antes eram solicitados diretamente no "balcão" do CNPq, hoje são vinculados às fundações

\footnotetext{
${ }^{9}$ CT Agro, Aero, Infra, Amazônia, Info, Biotecnologia, Mineral, Hidro, Saúde, Petro, Energia etc.

10 Emenda apresentada pelo deputado Florestan Fernandes (PT-SP) deu origem ao parágrafo quinto do artigo 218: "É facultado aos estados e ao Distrito Federal vincular parcela de sua receita orçamentária a entidades públicas de fomento ao ensino e à pesquisa científica e tecnológica". É este dispositivo legal que permite aos estados destinarem percentuais preestabelecidos de suas receitas às fundações de fomento à pesquisa." (Revista Pesquisa Fapesp, ano 19, n. 274, p. 27, dez. 2018) 11 A Constituição Estadual do Ceará, de 1989, por exemplo, determina que $2 \%$ da arrecadação tributária seja destinada a pesquisas científicas e tecnológicas, mas o percentual sempre ficou abaixo desse patamar, oscilando entre 0,5\% e 1\% (Revista Pesquisa Fapesp, ano 19, n. 274, p. 45, dez. 2018).
} 
estaduais, que trabalham cada vez mais imbricadas com as principais agências nacionais. Algumas universidades públicas também possuem suas próprias agências, fundações e fundos separados, que são geridos com o propósito de apoiar seus cursos e estudantes no que tange à pesquisa e desenvolvimento de inovações tecnológicas.

Em poucas décadas, o Brasil teve sua posição melhorada em alguns dos rankings de países que produzem ciência com qualidade no mundo. Isto se deve em grande parte as políticas de fomento à ciência e tecnologia promovidas pelo CNPq e ao empenho de mais de 80 mil pesquisadores brasileiros de todas as áreas. São muitos os exemplos de como a ciência brasileira produz conhecimento e alavanca a economia, transformando conhecimento em riqueza.

Foi a ciência brasileira que descobriu o pré-sal, mesmo que agora ele esteja sendo entregue às petroleiras multinacionais, ou será que alguém ainda tem dúvidas que o massacre contra a Petrobras tinha outro objetivo? Foram as pesquisas do Instituto Tecnológico de Aeronáutica (ITA) junto à Empresa Brasileira de Aeronáutica (Embraer) que transformou o Brasil num dos maiores e mais importantes produtores de aeronaves do mundo, mesmo que agora tudo esteja sendo perdido para a Boeing, entre tantos outros exemplos que poderiam ser dados.

Não são somente as ciências exatas ou as áreas da saúde que se destacam; todas as áreas do conhecimento têm sua relevância. Apenas a título de exemplo, poderíamos dizer que os geógrafos brasileiros têm dado imensa contribuição para o estudo da empiricização do tempo no espaço, nas diferentes escalas geográficas; para a compreensão da formação socioespacial brasileira; para o estudo da economia política da urbanização e das cidades; para a compreensão dos processos de reestruturação urbano-regional e o aumento das desigualdades socioespaciais promovido pela difusão do agronegócio globalizado, entre tantos outros exemplos.

\section{6: momento de inflexão}

Se quisermos pensar em uma periodização da evolução das políticas de fomento do $\mathrm{CNPq}$, teríamos inúmeras possibilidades e alguns marcos muito significativos. Gosto de citar o ano de 1999 como um deles. Neste ano foi lançado o Diretório dos Grupos de Pesquisa, quando o CNPq oficialmente começa a organizar uma base dos pesquisadores no país. Desde então, todos os pesquisadores estão cadastrados em algum grupo de pesquisa. O mesmo poderia ser dito da Plataforma 
Lattes, o verdadeiro "Facebook" da academia. Para os principais objetivos do presente texto, gostaria de destacar um ano recente, 2016, um genuíno ponto de inflexão para as políticas de financiamento da ciência, tecnologia e inovação no país.

Os retrocessos políticos desde então, que se agravam ainda mais com a posse do atual presidente da República, que tem por objetivo escancarar sem limites as portas para o capital privado, têm promovido um processo de desmonte do sistema de financiamento da pesquisa no Brasil. O cenário atual é de grave crise e cortes de orçamento no CNPq, assim como em toda a base de sustentação do ensino superior público, que efetivamente está ameaçada.

As políticas de fomento à educação, à ciência e à tecnologia refletem as escolhas políticas dos governos e, desta forma, dada a total falta de visão estratégica do atual, estamos efetivamente andando para trás e os avanços conseguidos pela área de CT\&I vêm sendo dia a dia desestabilizados.

Tudo que vivencio, seja como pesquisadora, seja como representante da área de Geografia Humana no Comitê de Assessoramento do CNPq desde final de 2014, me leva a apresentar para os leitores uma hipótese preocupante. Qual seria esta hipótese? A de que, mais do que cortes de verba para a pesquisa científica, estaria havendo quase um desmonte do CNPq. Quero dizer com isto que os cortes não afetam somente as bolsas, os financiamentos à pesquisa, mas todo o funcionamento da instituição, como se a mesma estivesse sendo aos poucos corroída por dentro.

Sei que corro o risco de adotar um tom alarmista, mas o objetivo é aproveitar a oportunidade, chamar atenção para o problema e levantar o debate sobre o mesmo, até porque com frequência temos sido atropelados pelos acontecimentos e não temos conseguido refletir criticamente sobre todos eles.

Aproprio-me do que a professora Fernanda da Fonseca Sobral (UnB) disse na primeira mesa desse Seminário: que estaríamos vivendo uma democracia rasurada. Outros neologismos ou metáforas poderiam ser utilizados para o caso do CNPq, ou seja, não é que ele deixou de existir, ele continua, mas ações e processos importantes estão sendo comprometidos, como se aos pouquinhos estivessem corroendo alguns dos pilares da instituição. Acredito que estes são sólidos, construídos ao longo de seus quase 70 anos, e ainda é tempo de parar estes processos, até por isso insisto na hipótese visando o debate sobre o tema.

Seria leviano de minha parte apresentar tal hipótese sem os elementos de argumentação para evidenciá-la. Assim sendo, vamos a alguns deles, objetivando melhor diagnosticarmos a situação, na expectativa de pensarmos em possibilidades 
de atuação e, diferente dos trabalhos científicos que realizamos, torcendo bastante para a hipótese não ser comprovada ao final desse turbilhão de horrores que estamos vivendo.

Imagino que seja de conhecimento geral que o orçamento do CNPq está em queda brutal desde o golpe de $2016 .{ }^{12}$ Isto se reflete na diminuição de editais, na falta de aumento do número de bolsas etc. No primeiro julgamento presencial ${ }^{13}$, ocorrido no final do segundo semestre de 2016, o primeiro após o golpe, os membros dos comitês de assessoramento (CA) fomos recebidos com a informação de que deveríamos trabalhar com um cenário de corte de $20 \%$ do número das bolsas de produtividade (PQ), Importante dizer que há anos o número de bolsas é muito inferior à demanda das áreas, especialmente considerando a velocidade do crescimento da pós-graduação nos últimos vinte anos.

Vale lembrar que cerca de dois meses antes do período deste julgamento, as universidades tinham recebido a informação de que o mais importante programa institucional de bolsas de iniciação científica do país, o CNPq/PIBIC, sofreria um corte de cerca de $20 \%$ para o ano seguinte. Destacando que as bolsas de iniciação científica são aquelas que possibilitam a inserção do aluno de graduação à pesquisa científica. Apesar de seu baixo valor, ${ }^{14}$ possibilitam que milhares de jovens deem os primeiros passos no aprendizado do fazer ciência, se familiarizem com os principais procedimentos metodológicos e é, sem dúvida alguma, um dos principais pilares para a construção de uma política científica e tecnológica sólida e responsável. Imagino que muitos dos que agora leem esse texto tiveram a veia para a pesquisa despertada neste importantíssimo momento da vida universitária. Eu me incluo neste grupo.

Neste momento houve também uma orientação para que alterássemos alguns procedimentos de organização dos resultados do julgamento, de maneira a facilitar a tomada de decisões para os possíveis cortes. Foi a gota d'água para os membros dos comitês de assessoramento presentes. ${ }^{15}$ Importante dizer que as semanas de

\footnotetext{
12 De maneira geral, é possível dizer que o corte geral é de cerca de $50 \%$. Este número não é exato, é maior para algumas coisas, menor para outras, mas é suficiente para que todos possam sentir o tamanho do problema. Os dados que cito são os mesmos que todos têm tido acesso pela imprensa e entidades associadas à ciência e tecnologia, tais como a SBPC.

${ }^{13}$ Os julgamentos ocorrem não só na sede do CNPq em Brasília, mas também à distância, via internet, através da Plataforma Carlos Chagas.

${ }^{14}$ Há anos o valor das bolsas de iniciação científica é de $R \$ 400,00$, o que daria menos da metade do salário mínimo de $R \$ 998,00$ vigente em 2019. Aproveito para lembrar que os valores das bolsas de maneira geral, de I.C. e de pós-graduação, estão congelados há muito tempo.

${ }^{15}$ É comum que as semanas de julgamento presencial no final do segundo semestre reúnam algumas centenas de membros dos CAs das diferentes áreas do conhecimento. É o momento de
} 
julgamento presencial nas instalações do CNPq em Brasília são momentos de muita ebulição, pois há uma grande concentração de representantes das várias áreas do conhecimento, de dezenas de universidades brasileiras. Por outro lado, as semanas de julgamento presencial são sempre muito pesadas no quesito quantidade de trabalho, que é muito grande.

Nesta semana em especial o trabalho foi algumas vezes maior, pois além do trabalho específico do julgamento do $P Q$ e das $B E$, tínhamos que fazer reunião de mobilização, reunião para redigir documentos, nos dividirmos para ligar para representantes de associações de classe, mandar e-mails, convocar a mídia, aproveitar a presença em Brasília para tentar conversar com algum deputado ou senador etc. Lançamos um documento público que teve impacto importante e, no final, obtivemos sucesso, ou ao menos pensamos que sim, pois não houve o corte do número das bolsas $P Q$, nem do Pibic. Vejam a qual situação chegamos, não conseguimos nenhuma nova bolsa, mas diante do quadro, não perder nenhuma entendemos como uma vitória.

Outro aspecto significativo associado à hipótese trabalhada neste ensaio diz respeito ao não lançamento de editais importantes, tais como o de Ciências Humanas $(\mathrm{CH})$. Quando foi lançado, este edital visava justamente dar mais oportunidade para a área, que sofre certa desvantagem em relação a outros editais, tais como o Universal. Da mesma forma, o de $\mathrm{CH}$ teve entre os objetivos de seu lançamento dar mais oportunidade para recém-doutores, jovens pesquisadores. ${ }^{16}$ Em 2018 já não houve o edital e no presente ano não há nenhuma informação que o mesmo sairá. Em 2017, por sua vez, ele foi lançado, mas totalmente descaracterizado do seu perfil, privilegiando exatamente características inversas das que fizeram com o que o mesmo passasse a existir, tal como projetos em rede, voltados para alguns objetivos específicos e com valores bastante altos, inviabilizando que fosse solicitado pelos que eram inicialmente o público-alvo.

O edital Universal é outro que vem tendo vários problemas. Todo começo de ano, os membros dos CAs são informados do calendário dos julgamentos do ano. Neste momento, ficamos sabendo, entre outras informações, quais serão os editais que teremos. Em 2018, quando recebemos o calendário, além do $\mathrm{CH}$ também não constava o julgamento do edital Universal, ou seja, eles não seriam lançados. No 
caso do Universal, pensamos que não sairia até mesmo porque o CNPq ainda não tinha concluído o pagamento da chamada de $2016 .{ }^{17}$

Não sei exatamente o que aconteceu, as justificativas dadas não pareceram muito plausíveis, mas o Universal acabou sendo lançado. Foi um processo atípico, até mesmo de forma um tanto atabalhoada, de última hora, com um intervalo de menos de dois meses entre o lançamento do edital e a publicação do resultado final. Um período extremamente curto para todos os procedimentos necessários, destacando que um processo deste tipo que chega à instituição é primeiro analisado pelos técnicos das áreas para verificação do enquadramento aos critérios do edital; depois, eles são enviados aos pareceristas ad hoc ${ }^{18}$, que têm em média um mês para a realização dos pareceres e inserção dos mesmos na plataforma Carlos Chagas do CNPq. ${ }^{19}$

Desta forma, o lançamento do edital de última hora acabou atropelando o calendário anual. A solicitação inicial pela coordenação à qual a Geografia está ligada era para que em uma semana ocorressem os julgamentos de todos os processos de PQs, do Universal e das BEs e isto é humanamente impossível, seja pela complexidade dos processos, seja pela quantidade de trabalho. ${ }^{20}$

Entre as consequências negativas de tudo isto, além do estresse e do excesso de trabalho, foi que cada área dentro do CA do qual a Geografia faz parte se reuniu em um momento diferente para conseguir dar conta da atividade. Isto é ruim, especialmente no momento atual, pois os julgamentos presenciais são os momentos de troca de ideias, de reavaliação dos critérios de julgamento, de pensarmos juntos sobre vários aspectos que se associam à atividade, de reivindicarmos coisas junto à coordenação da qual fazemos parte etc.

Outro aspecto a sustentar minha hipótese diz respeito ao fato de terem diminuído as reuniões do presidente do CNPq com todos os membros dos CAs. Na primeira metade de meu mandato como representante de área era comum, no primeiro dia das semanas de julgamento presencial, o presidente chamar uma reunião no final da tarde, no auditório, com todos os representantes presentes.

\footnotetext{
17 Em mesa redonda ocorrida na Reunião Regional da SBPC em Rio Verde, em maio de 2018, que discutiu as perspectivas para o futuro da ciência e inovação no país, o diretor de Ciências Agrárias, Biológicas e da Saúde do CNPq, Marcelo Morales, falando sobre o edital Universal, dizia que "faltam $\mathrm{R} \$ 85$ milhões para serem pagos aos cinco mil projetos contemplados pelo Edital Universal de 2016, o que impede também o lançamento do Edital de 2018." (Jornal da Ciência, SBPC, 17 mai. 2018).

18 De maneira geral, para uma parte importante dos editais, são pareceristas ad hoc os pesquisadores de produtividade (PQs).

${ }^{19}$ Não é incomum um parecerista receber vários processos de um mesmo edital para dar parecer.

20 Para o caso, eram cerca de 250 processos para serem julgados em cinco dias, por duas pessoas, lembrando que um processo é formado de inúmeros documentos e não só o projeto.
} 
Nestas reuniões, o presidente discutia a conjuntura, apresentava brevemente novos editais que estavam sendo pensados, falava de ingerências que estavam sendo feitas para captação de recursos, de problemas da instituição etc. Da mesma forma, podíamos fazer questões, sugestões e reivindicações. Considerava estes momentos como especiais, dada a presença de colegas de diversas áreas do conhecimento, de diferentes partes do país, com os quais podíamos dialogar, assim como com o presidente e alguns diretores da instituição.

O último presidente do CNPq antes do nomeado pelo golpista Michel Temer (2016-2018) chegou a fazer também reuniões em cada CA, além da reunião coletiva. Mas já não conheci pessoalmente o penúltimo presidente (2017-2018) e até o momento de redação desse texto ainda não tinha ocorrido nenhuma reunião presencial desde que o atual assumiu (2019) para saber se seguirá ou não a prática da reunião coletiva com os CAs. ${ }^{21}$ Será que estou conseguindo mostrar para os leitores que o problema não é só de corte de verbas?

Outro problema grave que vem acometendo os que ganharam alguns editais, sendo o Universal entre eles, é a incerteza quanto as datas de liberação das verbas. Até o momento, não tive notícias de que um pesquisador que tenha ganhado um projeto do edital Universal não tenha recebido a verba, mas o que tem ocorrido com frequência é a total falta de informação de como e quando isto vai ocorrer, o que tem gerado grande insegurança e prejuízos à consecução das pesquisas, quando não a inviabilidade total de realização das mesmas. Isto vem acontecendo com certa frequência neste período de participação no CA, mas é muito forte desde 2016.

Tudo isto sem falar nos cortes que os orçamentos dos projetos vêm sofrendo. Num primeiro momento, desde que exerço a atividade de representante, não era incomum alguns editais terem um item tratando de possíveis cortes nos orçamentos dos projetos. O edital indicava que, se um projeto tivesse a recomendação de corte maior do que $30 \%$ no orçamento, o projeto seria desclassificado.

Nos últimos editais julgados, é comum não haver menção a tais aspectos, mas é recorrente a realização de cortes como única possibilidade para viabilizar um maior número de projetos recomendados, mesmo que estes tenham que se reorganizar para serem realizados. ${ }^{22}$ Já tive notícias de pesquisadores que não

\footnotetext{
${ }^{21} \mathrm{Em}$ abril de 2020 fomos todos surpreendidos por uma nova troca do presidente do CNPq.

22 Vou citar um caso do último edital Universal (2018), naturalmente sem nomear o pesquisador. A solicitação foi feita no limite máximo da faixa de projetos até $R \$ 120.000,00$, mais uma bolsa de I.C. por 24 meses. Houve a aprovação de $\mathrm{R} \$ 34.000,00$ mais a bolsa de I.C., ou seja, o pesquisador irá receber (se tudo der certo, ninguém tem certeza), menos do que $30 \%$ do solicitado e no caso da
} 
aceitaram a situação, preferindo não assinar o termo de aceite, pois afirmavam que com a quantia de verba aprovada e sem saber quando iriam receber era melhor não assinar o termo de aceite, até mesmo porque a partir daí a pesquisa tem que ser realizada, da mesma forma que toda a prestação de contas (financeira e científica).

Cito agora um exemplo também muito significativo da situação presente do CNPq, mesmo que não tenha sido julgado em nosso CA, como é o caso dos projetos dos Institutos Nacionais de Ciência e Tecnologia (INCTs), que tiveram julgamento à parte dos CAs. A última edição dos INCTs, que são projetos de grande monta de verba, que já vêm com bolsas de várias modalidades associadas etc. Os editais dos INCTs são complexos e têm várias exigências que outros editais não apresentam, tais como a de serem redigidos em português e inglês, até porque em muitos casos são enviados também para consultores estrangeiros. Em sua última edição, a comunidade científica brasileira se mobilizou e foram apresentados centenas de projetos.

O número de processos aprovados no mérito científico foi grande: 252, mas somente 102 foram efetivamente financiados e, mesmo assim, com muitos cortes em seus orçamentos. Fiz parte da equipe de pesquisadores de um destes projetos que teve o mérito científico reconhecido, mas que não recebeu nenhuma verba. $A$ coordenadora do projeto, muito ativa, realizou vários movimentos buscando ter alguma posição do CNPq sobre a situação do projeto, pois o intervalo entre a data oficial no edital para divulgação do resultado e efetivamente a divulgação deste foi bem grande. Por outro lado, após a publicização do resultado oficial, ficou uma situação bastante indefinida, pois não foram recebidos os termos de aceite, que é uma espécie de "contrato" entre o CNPq e os pesquisadores, assinado pelos coordenadores dos projetos ganhadores.

Para encurtar a história, a coordenadora do projeto de INCT do qual eu fazia parte da equipe como pesquisadora, que acabou por se tornar uma espécie de porta-voz de um grupo de coordenadores de projetos de INCTs na mesma situação, e chegou até mesmo a se reunir pessoalmente para tratar do tema com o presidente do CNPq, recebeu a seguinte proposta: os projetos que obtiveram o mérito científico poderiam receber um carimbo de ser um projeto INCT do CNPq. O que isto significava exatamente: receber o carimbo e nenhuma verba e ter que realizar a 
pesquisa. Desculpem-me se parece que estou lhes dando "notícias do hospício", mas apenas relato os acontecimentos. ${ }^{23}$

Além do mais, naturalmente, diante do explanado acima, não houve mais nenhuma chamada para o INCT. Da mesma forma, outro edital muito importante que também não saiu mais foi o Casadinho/Procad. Trata-se de um edital visando um projeto coletivo que se realiza através de uma parceria entre dois programas de pósgraduação, um considerado consolidado (nota maior na Capes) e um considerado ainda não consolidado, e é resultado de uma associação entre o CNPq e a Capes. Uma de suas características mais interessantes é a de propiciar não somente a mobilidade de professores de um programa ao outro, através da realização das chamadas missões de docência e pesquisa, mas principalmente as missões de estudo, quando a mobilidade é também realizada pelos alunos associados ao projeto, normalmente orientandos dos pesquisadores do mesmo, que recebem bolsas para passar alguns meses até um ano no programa parceiro. ${ }^{24}$

Outro exemplo grave do que estou chamando de desmonte, talvez de forma um tanto exagerada, visando levantar o debate, pode ser dado para o caso que vem acontecendo com as Bolsas Especiais (BE), que são as bolsas de pós-doutorado (júnior e sênior), de doutorado sanduíche, de professor visitante e de doutorado pleno no exterior. As solicitações seguem um calendário fixo com três diferentes datas pré-estabelecidas durante o ano.

Durante o Enanpege ${ }^{25}$ de 2017, encontrei um colega que vinha tentando um pós-doutorado no exterior e já havia feito solicitação ao CNPq algumas vezes. Eu estranhei vê-lo, pois ele estava entre os projetos recomendados no último julgamento de então das BEs. Ingenuamente perguntei, meio fazendo a piada, se ele tinha voltado ao Brasil só para o Enanpege? Ele respondeu "não, novamente eu

\footnotetext{
23 Utilizo aqui "notícias do hospício" apropriando-me de título de uma coluna semanal da Carta Capital que relata o que aconteceu de mais lisérgico no que chamam de manicômio, referindo-se ao momento atual do Brasil.

${ }^{24}$ Fui coordenadora de dois projetos Casadinho/Procad. O primeiro, em parceria com o Programa de Pós-Graduação em Geografia da Unesp de Presidente Prudente, de 2006 a 2009. Foi este projeto que possibilitou a realização da primeira pesquisa coletiva da Rede de Pesquisadores sobre Cidades Médias (ReCiMe), que coordenei juntamente com um nome referência sobre o tema, a professora Maria Encarnação Beltrão Sposito, e que teve participação de vários outros colegas de inúmeras universidades do país, da Argentina e do Chile. O segundo projeto foi desenvolvido em parceria com o programa de Geografia da Universidade Federal Fluminense (UFF), de 2012 a 2016. Do primeiro para o segundo projeto, as normas tinham mudado e não havia mais a figura do vice-coordenador, ficando a cargo somente do programa não consolidado a coordenação do projeto. Desta forma, coordenei o segundo projeto, que teve a participação de cinco colegas do programa da UFF (Carlos Alberto Franco da Silva, Ester Limonad, Jacob Binszotk, Marcio Pinon e Rogério Haesbaert).
}

25 Encontro Nacional da Anpege. 
não consegui a bolsa". Não entendi nada, pois havia aproximadamente 15 projetos recomendados e o dele estava entre eles.

Assim que consegui, falei com a professora Monica Arroyo (USP), minha colega da Geografia Humana no comitê de assessoramento, e fomos atrás dos resultados na página do CNPq. Foi só aí que percebemos que somente um dentre todos os projetos que havíamos recomendado na modalidade tinha sido efetivamente agraciado com a bolsa. E assim vem sendo desde então.

Não era nossa prática ficar acompanhando os resultados quando publicados na página do CNPq, pois imaginávamos que nosso trabalho tinha sido feito e estava tudo certo. Mas, desde então, passamos a acompanhar os resultados e pudemos perceber que mais ou menos desde 2016, 2017, é assim que as coisas vêm acontecendo, o que me parece bastante preocupante!

Destaco que, após o julgamento realizado pelos CAs, os processos ainda percorrem outras instâncias internamente e, por fim, são estas que dão a última palavra. Assim, não é porque um projeto é recomendado no CA que ele é implementado. Talvez vários dos leitores já estiveram nesta situação, ou seja, que o projeto foi recomendado no mérito científico, mas não há verba para a implementação do mesmo.

Ainda apresentando os elementos de argumentação sobre certa corrosão nas engrenagens do CNPq, trato agora um pouco sobre seu corpo técnico. Como ocorre em várias outras instituições, quando há mudança do presidente, há uma série de reorganizações das coordenações e do corpo técnico de uma maneira geral, em especial para acomodar os "homens e mulheres de confiança" do mesmo.

Naturalmente, quando Michel Temer assumiu, ele trocou o presidente do CNPq. Este trouxe consigo algumas pessoas para ocupar postos chave. Corria à "boca pequena" que nem todos tinham as condições técnicas necessárias para assumir determinadas funções. Não tenho todos os elementos para afirmar se isto era ou não verdadeiro, pois não tive contato direto com tais pessoas, mas vale destacar que os técnicos do CNPq são profissionais muito bem qualificados para suas funções ${ }^{26}$.

Já que entramos no funcionamento interno, vamos então tratar de um dos pilares de funcionamento do CNPq: suas maravilhosas plataformas informatizadas. Temos a Plataforma Carlos Chagas, a Lattes, a dos Grupos de Pesquisa, entre 
outras. Tratemos de uma não tão conhecida ou utilizada por todos, a Carlos Chagas. Para termos noção da importância da mesma, basta lembrarmos que qualquer processo encaminhado ao CNPq deve ser feito por ela. Todo e qualquer bolsista ou beneficiário de algum tipo de recurso da instituição tem registro nesta base, desde o aluno de iniciação científica. Todo julgamento realizado pelos CAs é feito com base nos dados inseridos nesta plataforma.

Naturalmente estas bases não têm a mesma idade do $\mathrm{CNPq}$, são mais recentes, especialmente desde que a informática ganhou a importância que tem hoje em nossas vidas cotidianas. A questão é que o setor de informática também passou a apresentar problemas, gerando inúmeros outros, já que hoje todos os procedimentos da instituição dependem da informática. Têm sido comuns problemas nas diferentes plataformas, sentidos tanto internamente, quanto por todos os pesquisadores. Já citei como as semanas de julgamento presencial no CNPq são momentos de muito trabalho. Imaginem, então, perder todo o trabalho realizado no primeiro dia porque a informática não funcionou e não registrava as informações inseridas! Até isto já aconteceu. Imagino que não sejam coincidência os problemas terem sido agravados depois que o setor de informática foi terceirizado.

Bom, poderia dar ainda vários relatos e impressões do que me parecem situações de desmonte/crise/corrosão do CNPq, a partir de situações vividas como membro de comitê de assessoramento, mas penso que já é suficiente para demonstrar minhas inquietações. Espero que não considerem o tom excessivamente intimista, nem é o meu perfil, mas, como disse no início desse ensaio, pareceu-me importante socializar os aspectos abordados e assim, quem sabe, termos mais elementos para melhor avaliar a situação, visando sua transformação.

Tive muita dúvida se o tom era adequado, mas depois acabei concluindo que era uma oportunidade e destaco que minhas inquietações só aumentaram quando eu comecei a organizar a minha fala para o evento, pois até então nem eu mesma tinha juntado tantos acontecimentos num mesmo pensar. Daí a hipótese da corrosão interna parecer-me plausível.

\section{Perspectivas}

Não tenho dúvidas de que a graduação e a pós-graduação das universidades públicas serão rapidamente impactadas por todos estes processos. Estamos vivenciando dois movimentos que vão a sentidos opostos: o número de cursos e 
alunos da graduação e da pós-graduação cresceu muito nas últimas duas décadas e a verba para financiamento da pesquisa está agora em queda abrupta. ${ }^{27}$

Penso que todos já estamos sentindo o que tudo isto significa no nosso cotidiano: encolhimento da pesquisa pura, da pesquisa em rede; diminuição da cooperação e da mobilidade acadêmica; redução dos convênios e acordos bilaterais; decrescimento da interdisciplinaridade; restringimento da desconcentração da produção do conhecimento; comprometimento da formação de recursos humanos na graduação e na pós-graduação; minoração das possibilidades de influenciar políticas públicas etc., na contramão do que ocorria nos últimos quinze ou vinte anos.

Diante do quadro, parece-me que o mais importante agora é olhar para frente, é pensar o futuro. Os desafios que sempre foram grandes estão ainda maiores. Temos que considerar também a possibilidade de que, com o atual grupo à frente do poder federal, incluso o atual ministro da pasta da ciência e tecnologia, assim como da presidência do CNPq, que as verbas da instituição se voltem ainda mais para as ciências aplicadas, para apoiar áreas específicas que, de maneira equivocada, são tradicionalmente consideradas com maior e mais rápido retorno. Não por um acaso, há grandes chances de as áreas de pesquisa aeroespacial estarem entre as privilegiadas.

Isto poderá levar ao aumento das já significativas desigualdades entre as diferentes áreas do conhecimento, comprometendo a sempre frágil posição das ciências humanas. Como em outras áreas, tal como na Previdência, não se trata de falta de recursos, mas de escolhas políticas, de vontade política e, talvez, como tudo vem demonstrando, também de falta de visão estratégica e de conhecimento de como fazer. Mas, não se enganem, o pilar de todos os ataques ao ensino e à pesquisa públicos é, sem sombra de dúvida, o projeto do atual governo de acabar com as universidades públicas no país. Sem elas, não há nenhuma chance de algum dia termos diminuída nossa histórica desigualdade socioespacial.

É hora de repensar as estratégias de ação para o futuro, mas o futuro que já começa após a leitura desta oração, e lutar para que o financiamento à educação e à pesquisa científica seja público e parte de uma política de Estado e que não possa sofrer intervenções radicais a cada novo governo, como está acontecendo agora,

\footnotetext{
27 De acordo com os resultados da Avaliação Quadrienal 2017 da Capes, o Sistema Nacional da PósGraduação (SNPG) cresce de forma contínua, atingindo o crescimento de $25 \%$ de programas entre 2013 e 2016. Em dados absolutos, o sistema saltou de 3.337 para 4.175 programas nesse período.
} 
que colocam em risco a sobrevivência de todo o sistema de ensino e pesquisa públicos, construído ao longo de décadas.

Somo-me aos que defendem que gastos com ensino e pesquisa, ciência e tecnologia não constituem despesa, mas investimento, muito diferente do que costumam entender os que estão à frente das áreas econômicas. Nenhuma sociedade se constrói sem conhecimento, sem educação, sem ciência, sem pesquisa, que são pilares estruturais do desenvolvimento econômico e social.

Uma rápida pesquisa sobre o tema mostrará que são inúmeros os países que investiram suas maiores somas nestes setores exatamente nos momentos de piores crises econômicas e não o contrário, como não cansa de repetir, por exemplo, o atual ministro da educação. Isto porque as despesas em educação, ciência e tecnologia ampla e rapidamente se replicam, direta e indiretamente, na dinamização da economia, além de se constituírem no sustentáculo de todo país, por gerações.

Neste momento, precisamos pensar em algumas frentes de atuação visando reverter o quadro vigente. Citemos ao menos duas, uma mais específica, da comunidade científica e uma mais geral, da sociedade como um todo. São várias as vozes que têm afirmado que é importante que a sociedade melhor compreenda o que significam as universidades públicas e a pesquisa científica para o país. Enquanto isto não ocorrer será difícil ter o apoio da sociedade como um todo, que continuará acreditando nas fake news que têm se replicado pelas redes sociais, muitas delas inclusive a partir do próprio grupo de apoio do atual governo federal.

Uma coisa é certa, é hora de nos reinventarmos. Devemos entender que estamos terminando uma fase, um momento da política, da história, da economia, da pesquisa e uma nova está começando e não temos certeza de qual contorno terá. Mas isto vai depender muito da nossa força de reivindicação. Temos que lutar para defender a universidade pública, a pesquisa e a ciência brasileiras.

Precisamos pensar em quais são as formas de pressão, as resistências, quais os campos de atuação. Entendo que o contexto é tenebroso, no qual as situações de menos atendimento às demandas das ciências humanas devem se agravar. ${ }^{28}$ Talvez, uma das possibilidades de pressão possa ser junto às agências de fomento

\footnotetext{
${ }^{28}$ No momento da releitura desse texto, no início do mês de maio de 2020 , mais de um ano de sua redação, estava aberta a chamada anual do Pibic, cujas bolsas teriam vigência de agosto de 2020 a julho de 2021, e que não incluiu diretamente as áreas de Ciências Humanas, a não ser que, de acordo com a chamada, contribuíssem, em algum grau, para o desenvolvimento das Áreas de Tecnologias Prioritárias do MCTIC.
} 
estaduais; seria uma forma de divisão do trabalho a que talvez alguns consigam ter mais acesso diretamente.

Outra possibilidade é continuar lutando pela reivindicação para a formação de uma diretoria de Ciências Humanas $(\mathrm{CH})$ no $\mathrm{CNPq}$, que não existe. No último julgamento presencial na instituição do qual participei, no final de 2018, houve um momento de mobilização dos membros dos CAs presentes para reivindicar a formação de uma diretoria das $\mathrm{CH}$, já prevendo o aumento da fragilidade da área com a posse do novo governo federal. Foi redigido um documento e este foi entregue pessoalmente por alguns representantes ao então presidente do CNPq. Este documento cobrava uma maior atenção para a área e a concretização de uma diretoria de $\mathrm{CH}$ na instituição.

Termino destacando que precisamos estabelecer nossas estratégias de ação, pois sem elas não vamos chegar a lugar algum. Entendo que a metodologia científica serve para qualquer coisa na vida. Assim, está na hora de construirmos nosso projeto para enfrentar a nova realidade: estabelecer nossos objetivos, quais procedimentos para atingi-los e assim por diante. E este sim, deve ser um projeto em rede, que una a todos nós, de mãos dadas com as demais áreas do conhecimento, como de resto com toda a sociedade brasileira. O papel dos sindicatos, das entidades e das associações profissionais, como a Associação dos Geógrafos Brasileiros (AGB), a Associação Nacional de Pós-Graduação e Pesquisa em Geografia (Anpege), dentre outros, devem também ter papel primordial neste contexto. Só assim teremos alguma chance de reter os retrocessos do presente e desatar os nós que significam entraves para avançarmos na construção da emancipação social e da democracia, que estão bastante ameaçadas.

Caso contrário, direitos conquistados depois de décadas de luta pela sociedade continuarão sendo moeda de troca no balcão de negócios dos governos, com o incremento da reestruturação produtiva, do neoliberalismo, sob o comando do capital financeiro, com o acirramento das desigualdades socioespaciais e dos conflitos, no campo e nas cidades.

É o futuro que está em jogo. 
Denise Elias - Concepção. Elaboração do manuscrito, revisão e aprovação da versão final do trabalho

\section{FINANCIAMENTO}

Não se aplica.

\section{CONSENTIMENTO DE USO DE IMAGEM}

Não se aplica.

APROVAÇÃO DE COMITÊ DE ÉTICA EM PESQUISA

Não se aplica.

\section{CONFLITO DE INTERESSES}

Não se aplica.

\section{LICENÇA DE USO}

Este artigo está licenciado sob a Licença Creative Commons CC-BY. Com essa licença você pode compartilhar, adaptar, criar para qualquer fim, desde que atribua a autoria da obra.

\section{HISTÓRICO}

Recebido em: 17-05-2020

Aprovado em: 25-05-2020 